\title{
Role of Metabolic Risk Factors, Family History, and Genetic Polymorphisms (PPARY and TCF7L2) on Type 2 Diabetes Mellitus Risk in an Asian Indian Population
}

\author{
Plaban Chaudhuri $^{\mathrm{a}}$ Mithun Das $^{\mathrm{b}}$ Indrani Lodh ${ }^{\mathrm{c}}$ Riddhi Goswami ${ }^{\mathrm{a}}$ \\ aDepartment of Biotechnology, Heritage Institute of Technology, Kolkata, India; 'bepartment of Anthropology \& \\ Tribal Studies, Sidho-Kanho-Birsha University, Purulia, India; 'Urvaraa IVF Clinic, Kolkata, India
}

\section{Keywords}

Asian Indians - Type 2 diabetes . Family history of diabetes . Gene polymorphisms · PPARY $\cdot$ TCF7L2 $\cdot$ Birth outcomes

\begin{abstract}
Introduction: Women with family history of diabetes (FHD) are at significantly increased risk of developing gestational diabetes mellitus which may eventually lead to type 2 diabetes mellitus (T2DM) in later life. Objective: This study investigates the role of FHD on metabolic markers and gene polymorphisms and hence on T2DM susceptibility in nondiabetic pregnant women and the subsequent risks in their newborns. Materials and Methods: The present study was conducted on 200 healthy (nondiabetic and normotensive) adult Asian Indian women, including 100 with and 100 without FHD, living in and around Kolkata, India. During the gestational period, they were studied twice and followed up till delivery. During delivery, both mothers' venous blood and cord blood were collected to estimate serum CRP, glucose, and lipid profiles of the respective mothers and their newborns. Genotyping of PPARY and TCF7L2 polymorphisms was done from these blood samples. Results: A comparison of the metabolic variables among the subjects with and without FHD revealed significant differences among them. We also found close relationship between mothers and their
\end{abstract}

newborn babies in terms of both PPARY (rs1801282) C/G and TCF7L2 (rs7903146) C/T polymorphisms. More specifically, genotyping results for mothers with FHD and their newborn babies showed high concordance in inheritance of alleles: (i) for PPARy via the risk allele $\mathrm{G}(74.0 \%)$ which is carried over to the newborn babies (64.5\%) and (ii) for TCF7L2 via the risk allele $\mathrm{T}(73.0 \%)$ which is carried over to the newborn babies (68.5\%). Conclusion: This study leads to the conclusion that Asian Indian women population based in Kolkata, India, are ethnically and genetically predisposed to the risk factors of diabetes through FHD, which is reflected in their gestational phase, and it has a significant implication on their birth outcomes.

(c) 2021 S. Karger AG, Basel

\section{Introduction}

Metabolic syndrome (MetS) is the culmination of a number of risk factors which gives rise to a variety of potentially harmful diseases such as cardiovascular disease and more importantly development of type 2 diabetes mellitus (T2DM). There are a number of other factors which may give rise to MetS which include insulin resistance (IR), atherogenic dyslipidemia, obesity, genetic inheritance, and high blood pressure. MetS can cause a karger@karger.com

(c) 2021 S. Karger AG, Basel

www.karger.com/phg

Karger ${ }^{\prime}=$
Riddhi Goswami

Department of Biotechnology, Heritage Institute of Technology

Chowbaga Road, Anandapur

Kolkata 700107 (India)

riddhi.goswami@heritageit.edu 
5-fold increase in T2DM [1]. MetS along with IR raises the risk for heart disease and other health problems, such as diabetes and stroke. Since MetS also includes many of the causative agents of T2DM, it can be used as an indirect biomarker for detecting and eventual prevention of T2DM [2-4].

Diabetes mellitus, one of the major contributing factors of MetS, is caused by dysregulation of blood glucose. T2DM is the most common type of diabetes with a frequency of $90-95 \%$ of all diabetic cases. T2DM results from both genetic and lifestyle factors and is characterized by IR or its deficiency or both [5]. According to the International Diabetes Foundation (IDF), India is currently placed behind China in terms of diabetes $[6,7]$. Diabetes currently affects $>62$ million people in India and is estimated to cause 1 million deaths in India each year. It is estimated that with this rate of increase in T2DM cases, by 2035, India will have $>100$ million cases of T2DM. If not contained, then India will harbor one-fifth of total diabetic population in the world [3, 8-11].

A number of genes associated with T2DM have been identified in many different populations [12-16]. However, in these investigations, subjects were divided into 2 groups - the first group consisted of T2DM patients and the second group consisted of nondiabetic people as control. Another area of research related to T2DM has received much attention which investigates the birth outcomes of T2DM mothers. The focus of most of these investigations includes the assessment of risks of premature birth and perinatal complications such as macrosomia, hyperglycemia, cardiomyopathy, major congenital malformations, and even perinatal death [5, 17-22].

T2DM is associated with a number of single-nucleotide polymorphisms among which PPAR $\gamma$ and TCF7L2 are found to be very common genes among South Asian populations. Among various polymorphisms for PPAR $\gamma$, the $G$ allele of Pro 12 Ala polymorphism accounts for the majority of T2DM cases and is found to be most pronounced among T2DM patients. TCF7L2 has been implicated to cause T2DM via linkage disequilibrium through different haplotype combinations, and it has been found that US and Danish populations are more pronounced for developing T2DM via TCF7L2 linkage disequilibrium. The other factor which causes T2DM is obesity among Asian Indians where the most common polymorphism in TCF7L2 leading to T2DM is C to T polymorphism at rs7903146 [23, 24].

In this study, we have investigated the role of family history of diabetes (FHD) in nondiabetic pregnant women in terms of T2DM risk and how it can influence the newborns. For this purpose, we have carried out a longitudinal study on nondiabetic obstetric population based in Kolkata, India, with one set of population having FHD and the other set not predisposed to FHD. Blood samples were collected for both groups of mothers twice during the pregnancy period and also from cord blood of their corresponding newborn babies to analyze for any irregularities or significant differences in biochemical parameters. Genotyping of PPAR $\gamma$ (rs1801282) and TCF7L2 (rs7903146) polymorphisms was also carried out for both mothers and their corresponding newborns. To the best of our knowledge, till date there is no longitudinal study on Asian Indian population based in Kolkata relating to these risk factors of T2DM. This study thus correlates how family history and gene polymorphisms play important roles in increased susceptibility towards T2DM during pregnancy and subsequent risk transmission to the next generation of this Asian Indian population.

\section{Materials and Methods}

In this study, 200 healthy adult nondiabetic Asian Indian women population, including 100 without FHD (control) and 100 with FHD (case), were used to determine the risk for T2DM for both mothers and the newborns. Women whose parents (either or both) are diabetic for at least a year or more and presently under clinical medication were considered as cases. Table 1 provides a summary of the demographic profile of all participants in this study which includes age group, occupation, and community of the participants. This sample size was sufficient enough to test the research hypothesis at $5 \%$ level of significance with a statistical power of $90 \%(\beta=0.90)$.

Mothers' venous blood (collected twice during 12 and 30 weeks during the gestational period) and cord blood of their newborn babies were used to determine their risk associated with T2DM by estimating biochemical parameters such as fasting blood sugar, $\mathrm{CRP}$, triglycerides, HbAlc, and HDL cholesterol by using an Autoanalyzer (Robonik India) as per NCEP ATP Panel-III (International Diabetes Federation 2006) guidelines. Informed consent was obtained from all the subjects who participated in this study, and the study was approved by the Institutional Ethics Committee.

\section{Genotyping for PPARy}

Genomic DNA was isolated from the mother and newborn blood samples (with and without FHD) by using the HiPurA Blood Genomic miniprep kit (HiMedia, Pennsylvania, USA). PCR-RFLP analysis was performed for all samples for detecting PPAR $\gamma$ gene polymorphism using the following primers:

- Forward: 5'CCAATTCAAGCCCAGTCCTTTC3'.

- Reverse: 5'CAGTGAAGGAATCGCTTTCCG3'.

Using the Bio-Rad thermal cycler (MyCycler, Germany), each PCR was performed in a volume of $50 \mu \mathrm{L}$, including $100 \mathrm{ng}$ of genomic DNA, $10 \mathrm{pmol}$ of each primer, $0.8 \mathrm{mM}$ of deoxynucleotide triphosphates, and $0.5 \mathrm{U}$ of Taq DNA polymerase in the reaction buffer $\left(50 \mathrm{mmol} / \mathrm{L}\right.$ of $\mathrm{KCl}, 2.8 \mathrm{mmol} / \mathrm{L}$ of $\mathrm{MgCl}_{2}$, and $10 \mathrm{mmol} / \mathrm{L}$ 
Table 1. Demographic profile summary of study participants

\begin{tabular}{|c|c|c|c|c|c|c|}
\hline \multirow[t]{2}{*}{ Sl No. } & \multirow[t]{2}{*}{ Age group, years } & \multirow{2}{*}{$\begin{array}{l}\text { Subjects, } \\
n\end{array}$} & \multicolumn{2}{|c|}{ Occupation (subjects, $n$ ) } & \multicolumn{2}{|c|}{ Community (subjects, $n$ ) } \\
\hline & & & working & homemaker & Bengali & others \\
\hline 1 & 19-25 (with FHD) & 36 & 8 & 28 & 24 & 12 \\
\hline 2 & 19-25 (without FHD) & 26 & 6 & 20 & 17 & 9 \\
\hline 3 & 26-30 (with FHD) & 35 & 11 & 24 & 26 & 9 \\
\hline 4 & 26-30 (without FHD) & 32 & 4 & 28 & 26 & 6 \\
\hline 5 & 31-35 (with FHD) & 21 & 7 & 14 & 13 & 8 \\
\hline 6 & 31-35 (without FHD) & 35 & 10 & 25 & 28 & 7 \\
\hline 7 & 36-40 (with FHD) & 8 & 2 & 6 & 8 & 0 \\
\hline 8 & 36-40 (without FHD) & 7 & 3 & 4 & 5 & 2 \\
\hline
\end{tabular}

FHD, family history of diabetes.

Table 2. Baseline biochemical characteristics of the study population with respect to family history

\begin{tabular}{|c|c|c|c|c|c|c|}
\hline & $\begin{array}{l}\text { without FHD } \\
(n=100)\end{array}$ & $\begin{array}{l}\text { with FHD } \\
(n=100)\end{array}$ & $p$ value & $\begin{array}{l}\text { without FHD } \\
(n=100)\end{array}$ & $\begin{array}{l}\text { with FHD } \\
(n=100)\end{array}$ & $p$ value \\
\hline $\mathrm{TC}, \mathrm{mg} / \mathrm{dL}$ & $209.29 \pm 28.02$ & $281.01 \pm 48.47$ & $<0.05$ & $209.44 \pm 27.78$ & $289.59 \pm 47.16$ & $<0.05$ \\
\hline $\mathrm{TG}, \mathrm{mg} / \mathrm{dL}$ & $132.08 \pm 20.30$ & $205.00 \pm 22.42$ & $<0.05$ & $134.38 \pm 20.46$ & $223.64 \pm 22.45$ & $<0.05$ \\
\hline $\mathrm{FBS}, \mathrm{mg} / \mathrm{dL}$ & $104.74 \pm 19.14$ & $113.14 \pm 10.79$ & $<0.05$ & $104.66 \pm 18.75$ & $126.06 \pm 13.14$ & $<0.05$ \\
\hline $\mathrm{CRP}, \mathrm{mg} / \mathrm{L}$ & $2.06 \pm 8.43$ & $4.14 \pm 6.25$ & $<0.05$ & $1.21 \pm 0.39$ & $3.55 \pm 1.57$ & $<0.05$ \\
\hline
\end{tabular}

FHD, family history of diabetes.

of Tris- $\mathrm{HCl}, \mathrm{pH} 9.0$ ). For warming up, initial denaturation at $94^{\circ} \mathrm{C}$ for 3 min was carried out. Thereafter, denaturation at $94^{\circ} \mathrm{C}$ for 1 min, annealing at $55^{\circ} \mathrm{C}$ for $1 \mathrm{~min}$, and extension at $72^{\circ} \mathrm{C}$ for $1 \mathrm{~min}$ were performed for 30 cycles. Then, it was followed by a postextension at $72^{\circ} \mathrm{C}$ for $10 \mathrm{~min}$. In order to confirm the PCR amplification, gel electrophoresis ( $8 \%$ polyacrylamide gel and ethidium bromide staining) was carried out. Then, amplified products (244 bp) were digested by restriction endonuclease BstUI for rs1801282 (P12A) at $37^{\circ} \mathrm{C}$ for $1 \mathrm{~h}$. PCR amplification of the PPAR $\gamma$ gene produced a 244-bp DNA band. Digestion of this product with BstUI gave different patterns as follows: Pro12 homozygotes, Ala12 homozygotes, and heterozygotes were shown by 1 band ( $244 \mathrm{bp}), 2$ fragments (223 and $21 \mathrm{bp}$ ), and 3 fragments (244, 223, and $21 \mathrm{bp}$ ), respectively $[25,26]$.

\section{Genotyping for TCF7L2}

PCR-RFLP analysis was performed for all samples for detecting TCF7L2 gene polymorphism using the following primers:

- Forward: 5'AAGAGAAGATTCCTTTTTAAATGGTG3'.

- Reverse: 5'CCTCATACGGCAATTAAATTATACA3'.

A final reaction volume of $15 \mu \mathrm{L}$ of polymerase chain reaction contained $100 \mathrm{ng}$ of genomic DNA, 5 pmol of each primer, polymerase chain reaction buffer with $1 \mathrm{mmol} / \mathrm{L}$ of $\mathrm{MgCl}_{2}, 100 \mu \mathrm{mol} / \mathrm{L}$ of each deoxynucleotide triphospate (dNTP), and $0.5 \mathrm{U}$ of Taq polymerase. Polymerase chain reaction was carried out on a BioRad thermal cycler (MyCycler, Germany), under the following conditions: $95^{\circ} \mathrm{C}$ for $5 \mathrm{~min}$, followed by $58^{\circ} \mathrm{C}$ (for rs 7903146 ) for $30 \mathrm{~s}, 72^{\circ} \mathrm{C}$ for $30 \mathrm{~s}$, and a final extension of $72^{\circ} \mathrm{C}$ for $9 \mathrm{~min}$. Restriction fragment length polymorphism for rs7903146 (C/T) was carried out for the positive amplicons by digestion with the Hpy$\mathrm{CH} 4 \mathrm{III}$ enzyme at $37^{\circ} \mathrm{C}$ overnight, and the resulting products were electrophoresed on a $3 \%$ agarose gel. Digestion with Hpy-CH4III gave the following band patterns: $136 \mathrm{bp}$ (mutant homozygote TT), 112 bp (wild homozygote GG), and 2 bands at 136 and 112 bp (heterozygotes GT), respectively [27, 28].

\section{Results and Discussion}

\section{Biochemical Analysis of Metabolic Risk Factors}

Statistical analysis of the comparison of group differences (with and without FHD) for all the variables (12 and 30 weeks) was performed using the $t$ test $(p<0.05)$. Table 2 shows the biochemical parameters which were considered during the study. 
Table 3. Differences in birth outcomes (birth weight) and CRP levels in newborns by FHD and CRP of mothers

\begin{tabular}{|c|c|c|c|c|c|c|}
\hline \multirow[t]{2}{*}{ Mothers' status } & \multicolumn{3}{|c|}{ Birth weight of babies } & \multirow[t]{2}{*}{$p$ value } & \multirow{2}{*}{$\begin{array}{l}\text { CRP level } \\
\text { of babies, mg/L }\end{array}$} & \multirow[t]{2}{*}{$p$ value } \\
\hline & $\begin{array}{l}\text { normal } \\
(2.5-4.2 \mathrm{~kg})\end{array}$ & $\begin{array}{l}\text { overweight } \\
\text { (>4.2 kg) }\end{array}$ & total & & & \\
\hline Without FHD and normal CRP & 64 & 1 & 65 & \multirow{2}{*}{$<0.05$} & $0.85 \pm 0.17$ & \multirow{2}{*}{$<0.05$} \\
\hline With FHD and high CRP & 89 & 10 & 99 & & $3.33 \pm 0.89$ & \\
\hline
\end{tabular}

FHD, family history of diabetes.

A comparison of the biochemical characteristics among the subjects with and without FHD by the twotailed $t$ test revealed that there were significant differences among them with respect to triglycerides, total cholesterol, fasting blood sugar, HDL cholesterol, HbAlc (glycated hemoglobin), and CRP, both at the gestational period of 12 and 30 weeks, respectively. This indicates that family history plays a pivotal role in influencing metabolic variables and thus triggering the metabolic risk factors early in the gestational phase eventually leading to complications such as T2DM leading to MetS in later life.

Comparison of subjects with respect to the CRP levels between the groups by contingency $\chi^{2}$ analysis also revealed a statistically significant difference $(p<0.05)$ in the number of subjects with FHD and without FHD subjects (Table 3). It shows that there is a significant difference in CRP values between groups of mothers with and without FHD. This shows that mothers with FHD have a greater tendency towards a high inflammatory status.

Comparison of birth outcomes in terms of birth weights done between subjects with and without a positive family history of T2DM (i.e., FHD) and high CRP levels is also shown in Table 3, which revealed a significant difference between the 2 groups. It is evident from the results that there is a significant difference in inflammatory status in those newborns along with a prevalence of overweight babies in those mothers who have a positive FHD compared to their normal counterparts.

Newborn babies were classified with respect to the family history and CRP levels of their mothers, and then their CRP levels were compared as in Table 3. Comparison of CRP levels between these groups by the two-tailed $t$ test also revealed a statistically significant difference $(p<0.05)$ between the 2 groups of newborn babies. These findings suggest that family history and perturbations in the gestational period are reflected in the CRP status of the newborn babies and thus may influence the inflam- matory condition in those newborns whose mothers are with FHD compared to their normal counterparts.

\section{Genotyping of PPARy and TCF7L2 Genes}

Table 4 shows genotyping results of the PPAR $\gamma$ gene of newborn babies with respect to their mothers' FHD and genotypes. The genotyping results of PPAR $\gamma$ show that there is a greater tendency for mothers with FHD to progress to T2DM not only via the risk allele $\mathrm{G}(74.0 \%)$ but also to carry on the $G$ allele to their newborn babies $(64.5 \%)$ in the next generation.

PPAR $\gamma$ belongs to the nuclear receptor super family and is a ligand-activated transcription factor and can regulate nuclear hormone secretion such as steroid hormones $[25,29,30]$. As it belongs to a group of transcription factors, it can regulate genes [31]. It is known as an orphan receptor and also contains RXR receptors. Out of the 3 main subtypes, it is only the $\gamma$ subtype that is essential [32]. It plays an intricate role in adipogenesis but also has derived from thrifty genes. PPAR $\gamma$ has evolved and hence adapted through both thrifty genes and hostile environment. PPAR $\gamma$ works by binding of RXR as heterodimers and then binds to specific PPAREs in the promoter region of target genes. It can activate lipogenic activities in fat cells of the liver and adipose tissue resulting in insulin suppression. This results in the decrease of fatty acids with the result being to infiltrate other tissues and in the process to target insulin desensitization of fatty acids in the muscle and liver $[33,34]$. The overall effect is reduction in insulin sensitivity.

Pattanayak et al. [30] studied PPAR $\gamma$ (rs1801282) polymorphism and its propensity with T2DM in West Bengal population. They have conducted a study on 200 T2DM and 200 normal individuals and found that PPAR $\gamma$ was not directly associated with T2DM. In the study by Pattanayak et al. [30], CC, CG, and GG genotype frequencies for nondiabetic control were $79,18.5$, and $2.5 \%$, whereas the same for the T2DM case were $83.5,15$, and 
Table 4. Genotyping of PPAR $\gamma$ and TCF7L2 polymorphisms

\begin{tabular}{|c|c|c|c|c|c|}
\hline \multirow[t]{2}{*}{ Gene } & \multirow[t]{2}{*}{ Genotype } & \multicolumn{2}{|l|}{ Mother, $n(\%)$} & \multicolumn{2}{|l|}{ Baby, $n(\%)$} \\
\hline & & $\begin{array}{l}\text { without FHD } \\
(n=100)\end{array}$ & $\begin{array}{l}\text { with FHD } \\
(n=100)\end{array}$ & $\begin{array}{l}\text { without FHD } \\
(n=100)\end{array}$ & $\begin{array}{l}\text { with FHD } \\
(n=100)\end{array}$ \\
\hline \multirow[t]{5}{*}{$P P A R \gamma(\mathrm{rs} 1801282)$} & $\mathrm{CC}$ & $62(62.0)$ & $11(11.0)$ & $71(71.0)$ & $21(21.0)$ \\
\hline & CG & $38(38.0)$ & $30(30.0)$ & $29(29.0)$ & $29(29.0)$ \\
\hline & GG & $0(0)$ & $59(59.0)$ & $0(0)$ & $50(50.0)$ \\
\hline & C allele & $162(81.0)$ & $52(26.0)$ & $171(85.5)$ & $71(35.5)$ \\
\hline & G allele & $38(19.0)$ & $148(74.0)$ & $29(14.5)$ & $129(64.5)$ \\
\hline \multirow[t]{5}{*}{ TCF7L2 (rs7903146) } & $\mathrm{CC}$ & $59(59.0)$ & $6(6.0)$ & $69(69.0)$ & $11(11.0)$ \\
\hline & $\mathrm{CT}$ & $41(41.0)$ & $42(42.0)$ & $31(31.0)$ & $41(41.0)$ \\
\hline & TT & $0(0)$ & $52(52.0)$ & 0 & $48(48.0)$ \\
\hline & $\mathrm{C}$ allele & $159(79.5)$ & $54(27.0)$ & $169(84.5)$ & $63(31.5)$ \\
\hline & $\mathrm{T}$ allele & $41(20.5)$ & $146(73.0)$ & $31(15.5)$ & $137(68.5)$ \\
\hline
\end{tabular}

FHD, family history of diabetes.

$1.5 \%$, respectively. For their control group, frequency of the $\mathrm{C}$ allele was $88.25 \%$ and of the $\mathrm{G}$ allele was $11.25 \%$, and the same for the case was 91 and $9 \%$, respectively. In our study, CC, CG, and GG genotype frequencies for nondiabetic obstetric women without FHD (control) are 62,38 , and $0 \%$, whereas the same for nondiabetic obstetric women with FHD (case) are 11, 30, and 59\%, respectively. For our control group, frequency of the $\mathrm{C}$ allele is $81 \%$ and of the G allele is $19 \%$ and the same for the case is 26 and 74\%, respectively. Therefore, our results show occurrence of a very high percentage of the risk allele $G$ in mothers with FHD making this particular group of subjects highly susceptible to T2DM in the future, even though none of these subjects are clinically diagnosed as T2DM patients at present. It may also be noted that almost a similar trend is observed in genotype and allele frequencies for newborn babies of this group of mothers indicating their enhanced risk of T2DM in later life. Florez et al. [35] conducted an experiment on 3,548 diabetic prevention program participants and found that PP homozygotes are at greater risk of developing of T2DM compared to the protective effect of Ala carriers/Ala homozygotes due to thrifty gene hypothesis. Lyssenko et al. [36] conducted an investigation on 2,293 individuals participating in the Botnia study (Finland) to determine the effects of certain genes like PPAR $\gamma$ and their association with T2DM. Their investigation found out that it is PPAR $\gamma$ (P12A) among others that causes T2DM. Singh [24] observed that TCF7L2 is more prominent for T2DM among South Indians and Western Indian populations where rs12255372, rs7903146, and rs4506565 show asso- ciations with respect to T2DM. Thus, TCF7L2 variants are the leading cause of T2DM. Sanghera et al. [37] have observed and reported the role of some recently emerged loci/genes such as PPAR $\gamma$ and TCF7L2 and their relation with respect to T2DM in a high-risk population of Asian origin. All the above studies are in agreement with our findings highlighting the importance of TCF7L2 singlenucleotide polymorphisms in the susceptibility towards T2DM.

Table 4 also shows genotyping results of the TCF7L2 gene of newborn babies with respect to their mothers' FHD and genotypes. Genotyping results of TCF7L2 show that there is a greater tendency for mothers with FHD to progress to $\mathrm{T} 2 \mathrm{DM}$ via the risk allele $\mathrm{T}(73.0 \%)$ and also to carry on the $\mathrm{T}$ allele to their newborn babies (68.5\%) in the next generation.

One of the most potent genes with respect to T2DM is TCF7L2. They are involved in increased expression levels of genes of human islets and can also produce impaired insulin secretion. They also are involved in secreting enhanced impaired incretin effects particularly in those subjects who have pronounced risk-specific alleles for TCF7L2, and these result in the impact of the enteroinsular axis in T2DM. Villareal et al. [38] have shown that the mutant variant of TCF7L2 rs7903146 has caused T2DM by modifying the effect of incretin on insulin secretion. TCF7L2 not only causes altered islets but also alters the $\alpha$ to $\beta$ ratio within human islets [38].

In a Turkish population study, it has been shown that individuals who carry TCF7L2 rs7903146 polymorphism have a significant risk of T2DM [28]. To study the 
relationship between TCF7L2 and T2DM, 502 T2DM and 782 non-T2DM subjects were chosen by Zhu et al. [39]. They observed that $\mathrm{rs} 290481 \mathrm{~T}>\mathrm{C}$ is responsible for T2DM. We found similar results but with different polymorphic sites. In a study by Thorsby et al. [40], 869 individuals with T2DM and 2,080 without T2DM were considered from a large Norwegian population. The study concluded that alleles for the TCF7L2 gene (rs7903146) are highly associated with T2DM. Chandak et al. [41] reported the results of a study conducted on a Western Indian population based in Pune, Maharashtra, and found out that TCF7L2 is associated with T2DM. In this study, 955 T2DM patients and 399 nondiabetic patients were considered to find association between T2DM and TCF7L2. The genotype frequencies reported by Demirsoy et al. [28] for Turkish population, Thorsby et al. [40] for Norwegian population, and Chandak et al. [41] for Western Indian population for TCF7L2 (rs7903146) polymorphism are in the range of 51.4-58\% for CC, $10-40.1 \%$ for CT, and $6.1-32 \%$ for TT for control and the same for the case are in the range of 36$46.1 \%$ for CC, $22-46.2 \%$ for CT, and $7.8-42 \%$ for TT, respectively. In our study, for the same TCF7L2 (rs7903146) polymorphism, genotype frequencies for mothers without FHD are 59\% for CC, $41 \%$ for CT, and $0 \%$ for TT, whereas the same for mothers with FHD are $6 \%$ for CC, $42 \%$ for CT, and $52 \%$ for TT, respectively. However, it should be noted that in the present study, instead of T2DM patients as the case, nondiabetic obstetric Asian Indian population with FHD (i.e., mothers with FHD) is considered as the case. Nevertheless, it is observed that mothers with FHD are having a very high percentage of the risk allele $\mathrm{T}$, and thus they are highly susceptible to T2DM in later life. The reason is that TCF7L2 can influence both IR and insulin secretion, and this is a common factor for all these population groups. All the above reports are thus in concordance with our results. In our study, based on HbAlc data obtained from blood samples collected during the 30th week of pregnancy, we observed statistically significant difference between the average $\mathrm{HbAlc}$ levels for mothers without FHD (4.91 \pm 0.73$)$ and mothers with FHD (5.92 \pm 0.80 ). Further, for mothers with FHD, it is observed that average $\mathrm{HbAlc}$ levels for CT $(5.94 \pm 0.78)$ and TT $(6.00 \pm 0.80)$ genotypes are slightly elevated in comparison with the same for the CC $(5.88 \pm 0.64)$ genotype, but the differences are not statistically significant. A possible explanation for this observation is that our subjects (nondiabetic mothers with FHD) are not yet clinically diagnosed as T2DM patients.
The above genotyping results of PPAR $y$ and TCF7L2 genes suggest that mothers with FHD tend to cause the progression of risk alleles to the next generation via the following genotypes: (i) for the PPAR $\gamma$ gene via GG genotypes and (ii) for the TCF7L2 gene via TT genotypes. However, the disparity observed between groups of mothers with and without FHD in terms of both GG genotype for PPAR $\gamma$ (rs1801282) polymorphism and TT genotype for TCF7L2 (rs7903146) polymorphism is very high in the sample population based in Kolkata, India, used in our study. In the future, we intend to study using a larger sample size and also on other ethnic groups in India to find out whether or not the abovementioned disparity is an isolated observation.

\section{Conclusion}

This study suggests that patients carrying the $G$ allele (PPAR $\gamma$ ) and T allele (TCF7L2) may contribute to GD and eventually to T2DM. The etiology of GD involves a complex interplay of multiple genes and environmental and immunologic factors. Although no single theory can explain all cases, it seems that TCF7L2 gene polymorphism might be associated with increased risk of GD and eventually T2DM, whereas the thrifty genotype hypothesis explains the parental $G$ allele to be recognized as the risk allele for PPAR $\gamma$ mutation. Our statistical results further lead to the conclusion that T2DM of either or both grandparents (which is considered as "with FHD") may have an influence on the higher frequency of risk alleles G (PPAR $\gamma$ ) and T (TCF7L2) of the corresponding newborn babies through their mothers who also have a higher frequency of the G allele (PPAR $\gamma$ ) and T allele (TCF7L2). So, not only the mothers with FHD are at a greater risk of future T2DM but also their newborn babies. Therefore, this study linking 3 generations suggests that FHD is not only a risk factor but also a screening tool for detection and prevention of T2DM and other metabolic disorders for both mothers with FHD as well as their newborn babies.

\section{Acknowledgement}

The authors are grateful to the authorities of the Heritage Institute of Technology, Kolkata, India, for necessary help and support. 


\section{Statement of Ethics}

The study was approved by the "Institutional Ethics Committee" of the Heritage Institute of Technology (Ref No. HITK/IEC/ BT-01/20). All procedures performed in studies involving human participants were in accordance with the ethical standards of the institutional and/or national research committee (Ethical Guidelines for Biomedical Research on Human Participants, issued by the Indian Council of Medical Research 2006) and with the 1964 Helsinki Declaration and its later amendments or comparable ethical standards. Informed consent was obtained from all individual participants included in the study.

\section{Conflict of Interest Statement}

The authors have no conflicts of interest to declare.

The authors did not receive any funding.

\section{Author Contributions}

Plaban Chaudhuri was involved in the data collection, experimental work, manuscript drafting, and data analysis; Mithun Das helped in the study design; Indrani Lodh helped in the data collection; and Riddhi Goswami was involved in study design, manuscript drafting, and data analysis and interpretation.

\section{References}

1 Borch-Johnsen K. The metabolic syndrome in a global perspective. The public health impact: secondary publication. Dan Med Bull 2007;54(2):157-9.

2 Wilson PW, D'Agostino RB, Parise H, Sullivan L, Meigs JB. Metabolic syndrome as a precursor of cardiovascular disease and type 2 diabetes mellitus. Circulation. 2005;112(20): 3066-72.

3 Shaw JE, Chisholm DJ. 1: epidemiology and prevention of type 2 diabetes and the metabolic syndrome. Med J Aust. 2003;179(7): 379-83.

4 Desroches S, Lamarche B. The evolving definitions and increasing prevalence of the metabolic syndrome. Appl Physiol Nutr Metab. 2007;32(1):23-32.

5 Fraser A, Lawlor DA. Long-term health outcomes in offspring born to women with diabetes in pregnancy. Curr Diab Rep. 2014; 14(5):489.

6 International Diabetes Federation (2006) The IDF consensus worldwide definition of the metabolic syndrome. 2016. Available from: http: //www.idf.org/metabolicsyndrome. Accessed 2019 Nov 12.

7 Gale J. India's diabetes epidemic cuts down millions who escape poverty. 2010. Available from: https://www.bloomberg.com/news/articles/2010-11-07/india-s-deadly-diabetesscourge-cuts-down-millions-rising-to-middle-class. Accessed 2019 Nov 12.

8 Mohan V, Sandeep S, Deepa R, Shah B, Varghese C. Epidemiology of type 2 diabetes: Indian scenario. Indian J Med Res. 2007;125(3): 217-30.

9 Huizinga MM, Rothman RL. Addressing the diabetes pandemic: a comprehensive approach. Indian J Med Res. 2006;124(5):481-4.

10 Wild S, Roglic G, Green A, Sicree R, King H. Global prevalence of diabetes: estimates for the year 2000 and projections for 2030. Diabetes Care. 2004;27(5):1047-53.
11 Sicree R, Shaw J, Zimmet P. Diabetes and impaired glucose tolerance. In: Gan D, editor. Diabetes Atlas, International Diabetes Federation. 3rd ed. Belgium: International Diabetes Federation; 2006. p. 15-103.

12 Sethi S, Panjaliya RK, Kumar P, Gupta S, Bhanwer AJS. Comprehensive SNP analysis of genes in cholesterol metabolism (PGC 1 Alpha), insulin signaling (IRS1), potassium channel (KCNJ11) and glucose homeostasis (PI3K) in three diversified groups. J Diabetes Metab. 2015;6:531.

13 Ijaz A, Babar S, Sarwar S, Shahid SU, Shabana. The combined role of allelic variants of IRS-1 and IRS-2 genes in susceptibility to type 2 diabetes in the Punjabi Pakistani subjects. Diabetol Metab Syndr. 2019;11(1):64.

14 Sesti G. Insulin receptor substrate polymorphisms and type 2 diabetes mellitus. Pharmacogenomics. 2000;1(3):343-57.

15 Singh SP, Raza ST, Mahdi F. Role of CAPN10, TCF7L2, PPARG and KCNJ11 gene in type 2 diabetes mellitus (T2DM). Era J Med Res. 2018;5(2):166-9.

16 Sanghera DK, Ortega L, Han S, Singh J, Ralhan SK, Wander GS, et al. Impact of nine common type 2 diabetes risk polymorphisms in Asian Indian Sikhs: PPARG2 (Pro12Ala), IGF2BP2, TCF7L2 and FTO variants confer a significant risk. BMC Med Genet. 2008;9:59.

17 Clausen TD, Mathiesen E, Ekbom P, Hellmuth E, Mandrup-Poulsen T, Damm P. Poor pregnancy outcome in women with type $2 \mathrm{di}$ abetes. Diabetes Care. 2005;28(2):323-8.

18 Jang HJ, Kim HS, Kim SH. Maternal and neonatal outcomes in Korean women with type 2 diabetes. Korean J Intern Med. 2018;33(6): 1143-9.

19 Hawthorne G, Robson S, Ryall EA, Sen D, Robarts SH, Ward Platt MP. Prospective population based survey of outcome of pregnancy in diabetic women: results of the Northern Diabetic Pregnancy Audit, 1994. BMJ. 1997;315: $279-81$.

20 Mi D, Fang H, Zhao Y, Zhong L. Birth weight and type 2 diabetes: a meta-analysis. Exp Ther Med. 2017;14(6):5313-20.
21 Negrato CA, Mattar R, Gomes MB. Adverse pregnancy outcomes in women with diabetes. Diabetol Metab Syndr. 2012;4(1):41.

22 Ogata ES. Problems of the infant of the diabetic mother. NeoReviews. 2010;11(11): e627-31.

23 Ruiz-Narvaez E. Is the Ala12 variant of the PPARG gene an "unthrifty allele"? J Med Genet. 2005;42(7):547-50.

24 Singh S. The genetics of type 2 diabetes mellitus: a review. J Sci Res. 2011;55:35-48.

25 Motavallian A, Andalib S, Vaseghi G, Mirmohammad-Sadeghi H, Amini M. Association between PRO12ALA polymorphism of the PPAR- $\gamma 2$ gene and type 2 diabetes mellitus in Iranian patients. Indian J Hum Genet. 2013; 19(2):239-44

26 Priya SS, Sankaran R, Ramalingam S, Sairam T, Somasundaram LS. Genotype phenotype correlation of genetic polymorphism of PPAR gamma gene and therapeutic response to pioglitazone in type 2 diabetes mellitus: a pilot study. J Clin Diagn Res. 2016;10(2):FC11-4.

27 Bodhini D, Radha V, Dhar M, Narayani N, Mohan V. The rs12255372(G/T) and rs7903146(C/T) polymorphisms of the TCF7L2 gene are associated with type 2 diabetes mellitus in Asian Indians. Metab Clin Exp. 2007;56(9):1174-8

28 Demirsoy IH, Aras N, Cinkir U. TCF7L2 rs7903146 gene variation is associated with risk of type 2 diabetes in Turkish population. J Clin Med Genomics. 2016;4(1):1.

29 Tripathi AK, Shukla S, Dwivedi MK, Tripathi JK, Singh S, Chauhan M, et al. Type 2 diabetes in a central Indian population: association with PPARG2 P121A allele but not ENPP1 K121Q. Adv Genomics Genet. 2013;3:1-9.

30 Pattanayak AK, Bankura B, Balmiki N, Das TK, Chowdhury S, Das M. Role of peroxisome proliferator-activated receptor gamma gene polymorphisms in type 2 diabetes mellitus patients of West Bengal, India. J Diabetes Investig. 2014;5(2):188-91.

31 Anghel SI, Wahli W. Fat poetry: a kingdom for PPAR gamma. Cell Res. 2007;17(6):486511. 
32 Ehrmann J Jr, Vavrusová N, Collan Y, Kolár Z. Peroxisome proliferator-activated receptors (PPARs) in health and disease. Biomed Pap. 2002;146(2):11-4.

33 Semple RK, Chatterjee VK, O’Rahilly S. PPAR gamma and human metabolic disease. J Clin Invest. 2006;116(3):581-9.

34 Haseeb A, Iliyas M, Chakrabarti S, Farooqui AA, Naik SR, Ghosh S, et al. Single-nucleotide polymorphisms in peroxisome proliferatoractivated receptor gamma and their association with plasma levels of resistin and the metabolic syndrome in a South Indian population. J Biosci. 2009;34(3):405-14.

35 Florez JC, Jablonski KA, Sun MW, Bayley N, Kahn SE, Shamoon H, et al. Effects of the type 2 diabetes-associated PPARG P12A polymorphism on progression to diabetes and response to troglitazone. J Clin Endocrinol Metab. 2007;92(4):1502-9.
36 Lyssenko V, Almgren P, Anevski D, OrhoMelander M, Sjögren M, Saloranta C, et al. Genetic prediction of future type 2 diabetes. PLoS Med. 2005;2(12):e345-308.

37 Sanghera DK, Ortega L, Han S, Singh J, Ralhan SK, Wander GS, et al. Impact of nine common type 2 diabetes risk polymorphisms in Asian Indian Sikhs: PPARG2 (Pro12Ala), IGF2BP2, TCF7L2 and FTO variants confer a significant risk. BMC Med Genet. 2008;9:59.

38 Villareal DT, Robertson H, Bell GI, Patterson BW, Tran $\mathrm{H}$, Wice $\mathrm{B}$, et al. TCF7L2 variant rs7903146 affects the risk of type 2 diabetes by modulating incretin action. Diabetes. 2010; 59(2):479-85.
39 Zhu L, Xie Z, Lu J, Hao Q, Kang M, Chen S, et al. rs290481T $>$ C polymorphism is associated with an increased risk of type 2 diabetes mellitus and fasting plasma glucose level. Oncotarget. 2017;8(44):77000-8.

40 Thorsby PM, Midthjell K, Gjerlaugsen N, Holman J, Hanssen KF, Birkeland KI, et al. Comparison of genetic risk in three candidate genes (TCF7L2, PPARG, KCNJ11) with traditional risk factors for type 2 diabetes in a population-based study: the HUNT study. Scand J Clin Lab Invest. 2009;69:282-7.

41 Chandak GR, Janipalli CS, Bhaskar S, Kulkarni SR, Mohankrishna P, Hattersley AT, et al. Common variants in the TCF7L2 gene are strongly associated with type 2 diabetes mellitus in the Indian population. Diabetologia. 2007;50(1):63-7. 